\title{
Involvement of RNase 7 in the malignant potential of oral squamous cell carcinoma cells
}

\author{
PUJA NEOPANE ${ }^{1}$, YOSHIHITO KURASHIGE ${ }^{2}$, KOKI YOSHIDA $^{1}$, OSAMU UEHARA $^{3}$, \\ DURGA PAUDEL $^{1}$, TETSURO MORIKAWA ${ }^{1}$, JUN SATO $^{1}$, MASATO SAITOH $^{2}$ and YOSHIHIRO ABIKO ${ }^{1}$ \\ ${ }^{1}$ Department of Human Biology and Pathophysiology, Division of Oral Medicine and Pathology, School of Dentistry; \\ ${ }^{2}$ Department of Oral Growth and Development, Division of Pediatric Dentistry, Graduate School of Dentistry; \\ ${ }^{3}$ Department of Oral Growth and Development, Division of Disease Control and Molecular Epidemiology, \\ School of Dentistry, Health Sciences University of Hokkaido, Hokkaido 061-0293, Japan
}

Received February 9, 2020; Accepted June 12, 2020

DOI: $10.3892 /$ or.2020.7678

\begin{abstract}
RNase 7 is involved in the innate immunity of the oral epithelium. Variations in the expression levels of RNase 7 have been reported in cutaneous squamous cell carcinoma, but not in oral squamous cell carcinoma (OSCC). The present study investigated the expression levels of RNase 7 in OSCC and its role in the malignant potential of these cells. The localization of RNase 7 in OSCC tissue sections was determined via immunohistochemistry. Positive staining for RNase 7 was observed around the epithelial pearls and spinous cells of the OSCC tissues. Four different types of OSCC cell lines (OSC-19, BSC-OF, SAS, and HSC-2) and a normal keratinocyte (HaCaT) were used. The mRNA and protein expression levels of RNase 7 were significantly higher in the OSCC cells compared to the $\mathrm{HaCaT}$ cells. Based on our hypothesis that high levels of RNase 7 expression may be involved in the malignant potential of OSCC cells, the effect of RNase 7 knockdown on both proliferation and invasion were evaluated by transfecting the cells with siRNA. Cell numbers, cell invasion, and MMP 9 expression levels were significantly higher in the siRNA-BSC-OF, -SAS, and -HSC-2 cells compared to the BSC-OF, SAS, and HSC-2 cells. The extent of differentiation of the siRNA-OSCC cells was examined using the differentiation and undifferentiation markers involucrin (INV) and K14, respectively. The expression level of K14 was significantly higher in the siRNA-OSCC cells compared to the OSCC cells. Alternatively, HSC-2 and SAS cells demonstrated higher expression levels of INV compared to the siRNA-HSC-2 and -SAS cells. These findings indicate that RNase 7 may
\end{abstract}

Correspondence to: Dr Yoshihiro Abiko, Department of Human Biology and Pathophysiology, Division of Oral Medicine and Pathology, School of Dentistry, Health Sciences University of Hokkaido, 1757 Kanazawa, Ishikari-Tobetsu, Hokkaido 061-0293, Japan

E-mail: yoshi-ab@hoku-iryo-u.ac.jp

Key words: antimicrobial peptide, RNase 7, OSCC, siRNA contribute to the suppression of the malignant potential of OSCC.

\section{Introduction}

RNase 7, an antimicrobial peptide (AMP) with ribonuclease activity, belongs to the RNase A superfamily and was first identified in squamous epithelium obtained from healthy skin (1). It is constitutively expressed in many types of epithelial tissues, such as those of the genitourinary, respiratory, and gastrointestinal systems, including the oral epithelium (1-4). The expression of this peptide is induced by stimulation with several types of microorganisms and pro-inflammatory cytokines $(1,5,6)$. Other types of epithelial AMPs, such as human beta-defensins (hBD), psoriasin, cathelicidin (LL-37), and calprotectin, have been involved in various epithelial diseases, including inflammatory diseases and cancer (7-13). In cancer, the AMPs were found to be involved in both tumor suppression and progression $(8,9,11)$. For example, hBD-1 and -2 may function as tumor suppressors, whereas hBD-3 is often associated with tumor progression (8). Although RNase 7 has been detected in the oral epithelium (4), its role in malignancy remains unknown. A recent immunohistochemical study indicated that the levels of RNase 7 gradually reduced with the progression of cancer in the skin, suggesting that the peptide may act as a tumor suppressor (14). Nonetheless, biological evidence of the involvement of RNase 7 in malignant tumors has not been presented thus far. Therefore, the aim of the present study was to evaluate the expression patterns of RNase 7 in oral squamous cell carcinoma (OSCC) in vitro and in vivo, and examine whether alterations in the expression levels of this gene affected the malignant potentialities of the cancer cells.

\section{Materials and methods}

Tissue samples. Tissue sections of patients at the Department of Oral Medicine and Pathology, at the Health Sciences University of Hokkaido (Hokkaido, Japan) were collected. The study was designed to include 20 specimens from OSCC patients (well-differentiated OSCC, 7; moderately-differentiated OSCC, 7; poorly-differentiated OSCC, 6); adjacent 
normal oral epithelium was used as healthy control. The differentiation stages of all the samples were determined by an experienced pathologist.

The protocol for the study was approved by the ethics review board of the Health Sciences University of Hokkaido.

Immunohistochemistry. Formalin-fixed paraffin-embedded sections obtained from the tissue samples were deparaffinized in xylene, rehydrated in ethanol series, and rinsed with demineralized water. Antigen binding sites were exposed using the heat-induced antigen retrieval method in a pressure cooker containing citrate buffer ( $\mathrm{pH}$ 6.0). Endogenous peroxidase activity was blocked with $3 \%$ hydrogen peroxide for $10 \mathrm{~min}$. Primary antibody [anti-RNase 7 antibody (CL0224); dilution, 1:50; catalog number, ab 154143; Abcam] was added and incubated for $1 \mathrm{~h}$ at $37^{\circ} \mathrm{C}$. After washing with PBS, $100 \mu \mathrm{l}$ of the secondary antibody (HRP-labeled polymer anti-mouse antibody; Dako EnVision + System, Dako North America, Inc.) was added to the sections, which were then incubated for $30 \mathrm{~min}$ at $37^{\circ} \mathrm{C}$. The sections were visualized with DAB (3,3'-diaminobenzidine; code K3468; Dako North America, Inc.) for $3 \mathrm{~min}$ at room temperature, followed by immersion in distilled water to avoid overstaining. Subsequently, the sections were counterstained with hematoxylin, dehydrated, and mounted in malinol. Normal rabbit serum was used instead of the primary antibody for the negative controls. The sections were observed under a light microscope (Olympus BX 50, Olympus Corporation) and the expression levels of RNase 7 were evaluated based on the intensity of staining (brown color). The findings were interpreted using the following scores: Negative, no reactivity; weakly positive, mild brown-colored staining; positive, immunoreactivity showing brown-colored staining of moderate intensity; and strongly positive, strong brown-colored staining.

Cell culture. Four different types of OSCC cell lines (BSC-OF, SAS, OSC-19, and HSC-2) and an immortalized human keratinocytes cell line (HaCaT) were used in this study. BSC-OF was isolated from excised tissues diagnosed as basaloid-squamous cell carcinoma of the floor of the mouth, and cultured in our laboratory (15). OSCC cell lines SAS, HSC-2 and OSC19 were obtained from the Human Science Research Resource Bank (Osaka, Japan). HaCaT was obtained from Cell Line Services (CLS, Germany). The cells were grown in Dulbecco's modified Eagle's medium (DMEM; Sigma-Aldrich Biotechnology) supplemented with $10 \%$ fetal bovine serum (FBS; Invitrogen), $2 \% 100 \mathrm{IU} / \mathrm{ml}$ penicillin and $100 \mathrm{IU} / \mathrm{ml}$ streptomycin (Sigma-Aldrich) at $37^{\circ} \mathrm{C}$ in a humidified atmosphere and $5 \% \mathrm{CO}_{2}$.

Reverse transcription-quantitative polymerase chain reaction. Total RNA was extracted from the cell lines using the acid guanidine thiocyanate/phenol-chloroform method with TRIzol ${ }^{\circledR}$ (Invitrogen) according to the manufacturer's instructions. The RNA was reverse transcribed using oligo (dT) 12-18 primers (Invitrogen), Superscript II reverse transcriptase (SuperScript Reverse Transcriptase; Invitrogen), DTT, and dNTPs. Nucleotide contents were measured on a nanodrop ND-1000 spectral photometer (Nanodrop Technologies). Reverse transcription-quantitative polymerase chain reaction
(RT-qPCR) was performed using the KAPA SYBR Fast qPCR Kit (Nippon Genetics); cDNA was mixed with the primer and RT-qPCR was performed on a Light Cycler $^{\circledR}$ Nano System (Software version 1.1, Roche Diagnostics). The following RNase 7 primers were used in the study: Forward-GGAGTC ACAGCACGAAGACCA, and reverse CATGGCTGAGTT GCATGCTTGA. The PCR conditions included denaturation at $95^{\circ} \mathrm{C}$ for $10 \mathrm{~min}, 45$ cycles of denaturation at $95^{\circ} \mathrm{C}$ for $10 \mathrm{sec}$, and annealing at $60^{\circ} \mathrm{C}$ for $30 \mathrm{sec}$. The relative mRNA expression levels were calculated using the $\Delta \Delta \mathrm{Cq}$ method (16). The experiment was performed in triplicate and values were normalized to GAPDH (forward: GAGTCAACGGAT TTGGTCGT and reverse: GACAAGCTTCCCGTTCTCAG primers) as a reference gene. Data were expressed as the ratio of the target mRNA to the GAPDH mRNA.

Immunocytochemical examination of RNase 7 in the cultured cells. Approximately 50,000 cells/well were seeded on sterilized chamber slides and left to grow overnight. After $24 \mathrm{~h}$, the cells were fixed in $95 \%$ alcohol for $5 \mathrm{~min}$ at room temperature and immunostaining was carried out using the primary antibody (CL0224; dilution, 1:50; catalog number ab 154143; Abcam). The subsequent steps were performed as described for the immunohistochemistry protocol under the same conditions.

Enzyme-linked immunosorbent assay. The OSCC and HaCaT cells were seeded at a density of $5 \times 10^{6}$ cells/well for three days. The supernatant was collected and centrifuged at 4,760 $\mathrm{x}$ g for $5 \mathrm{~min}$ at $4^{\circ} \mathrm{C}$. Subsequently, the supernatant was separated from the cell debris and stored at $-80^{\circ} \mathrm{C}$. To collect the cell extract, the cells in the wells were scraped and mixed with $1 \mathrm{ml}$ of cell lysate. After $30 \mathrm{~min}$, the lysate was centrifuged at $11,290 \mathrm{x} \mathrm{g}$ for $10 \mathrm{~min}$ at $4^{\circ} \mathrm{C}$; the cell extract was collected and stored at $-80^{\circ} \mathrm{C}$. The concentration of RNase 7 was determined by enzyme-linked immunosorbent assay (ELISA; Hycult Biotech) according to the manufacturer's instructions.

Knockdown of RNase 7 in OSCC cells. The OSCC and HaCaT cells were seeded in a 6-well plate at a density of $1 \times 10^{6}$ cells/well and incubated in $2 \mathrm{ml}$ of DMEM supplemented with $10 \%$ FBS without antibiotics, at $37^{\circ} \mathrm{C}$ with $5 \% \mathrm{CO}_{2}$. The next day, the cells were transfected with 100 pmol of RNase 7 siRNA and 100 pmol of the negative control siRNA (control) in test and control wells, respectively, along with the transfecting reagent containing Lipofectamine 2000 (Life Technologies) and an optimum medium. After $24 \mathrm{~h}$ of transfection, total RNA was extracted using the acid guanidine thiocyanate/phenol-chloroform method. The RNA was reverse transcribed to cDNA and RNase 7 mRNA expression was determined in both the negative control and the siRNA-OSCC cells via RT-qPCR.

Cell proliferation. The CyQUANT ${ }^{\circledR}$ cell proliferation assay (Invitrogen) was used for the cell proliferation assay. The standard curve was prepared according to the manufacturer's instruction. In brief, the OSCC and HaCaT cells were seeded in 96-well plates (Corning Incorporated; surface area, $0.3 \mathrm{~cm}^{2} /$ well; density of $1 \times 10^{4}$ cells/well) and incubated in $100 \mu \mathrm{l}$ of DMEM supplemented with $10 \%$ FBS without antibiotics. After $24 \mathrm{~h}$, the cells were transfected with 5 pmol siRNA along with the transfecting 
media. After 24 and $48 \mathrm{~h}$ of incubation, the wells were stored at $-80^{\circ} \mathrm{C}$ for two days to lyse the cells. The cells were thawed at room temperature; $200 \mu \mathrm{l}$ of CyQUANT GR dye/cell-lysis buffer (Invitrogen) was added to the well and incubated for $5 \mathrm{~min}$ at room temperature in the dark. The fluorescence of the nucleic acid was measured using a fluorescence microplate reader with filters appropriate for $480 \mathrm{~nm}$ excitation and $520 \mathrm{~nm}$ emission. The fluorescence values were converted into DNA concentrations and measured using a standard curve.

Invasion assay. Cell invasion was evaluated using a 24-multiwell Falcon TC Companion plate with Falcon cell culture inserts containing an $8.0-\mu \mathrm{m}$ pore size PET membrane with a thin layer of Matrigel basement membrane matrix (Corning Biocoat Matrigel Invasion Chamber). The experiment was carried out according to the manufacturer's instructions. In brief, $500 \mu \mathrm{l}$ of a suspension of OSCC cells $\left(2.5 \times 10^{4}\right.$ cells) and $\mathrm{HaCaT}$ were grown in the serum media within the insert. After $24 \mathrm{~h}$, the cells were transfected with 20 pmol of siRNA along with the transfecting reagent. The transfected cells were allowed to invade through the Matrigel matrix for $24 \mathrm{~h}$. The non-invading cells were removed and invading cells were stained with Diff-Quick stain $\left(\right.$ Hemacolor $\left.^{\circledR}\right)$. Images of the invaded cells were taken from three fields at high power. The numbers of invaded cells were counted using the ImageJ software, version $1.5 \mathrm{ob}$ (National Institute of Health).

$R T-q P C R$ for expression of matrix metalloproteinase 9, involucrin, and K14. The mRNA expression levels of matrix metalloproteinase (MMP) 9, involucrin (INV), and K14 were determined by RT-qPCR in both the control and knockdown OSCC cells. The primers used were: MMP-9 (forward: GGC AATGCTGATGGGAAACC, reverse: CTTGTCCCGGTC GTAGTTGG); INV (forward: ATGCCAGAAGGTGCCTGT CGA, reverse: TGTGTTTTCTCCTGCTTAAGC); and K14 (forward: GCCTCTCAGGGCATTCATCTC, reverse: GAG TGTGGAAGCCGACATCA).

Statistical analysis. Statistical analysis was performed using the IBM SPSS Statistical tool for iOS (Version 25; SPSS Inc.). The results were compared using the Mann-Whitney U test and Student's t-test for two groups and one way of variance (ANOVA) followed by Dunnett's post hoc test for multiple groups. $\mathrm{P}<0.05$ was considered statistically significant.

\section{Results}

Immunohistochemical localization of RNase 7 was observed in the OSCC tissue sections. Weak immunoreaction for RNase 7 was localized mainly in the surface layers of the normal oral epithelium adjacent to the tumor (Fig. 1). In well-differentiated OSCC, intense immunostaining was observed in the keratinized layers of the epithelial pearl and the intercellular spaces of the tumor nests (Fig. 2A and B). In moderately differentiated OSCC, positive staining was often strongly observed in the nuclei and cytoplasm of cells in the tumor nests that exhibited some keratinization (Fig. 2C and D), whereas weak immunoreaction was observed in some tumor cells that did not exhibit any keratinization. Tumor cells with no keratinization

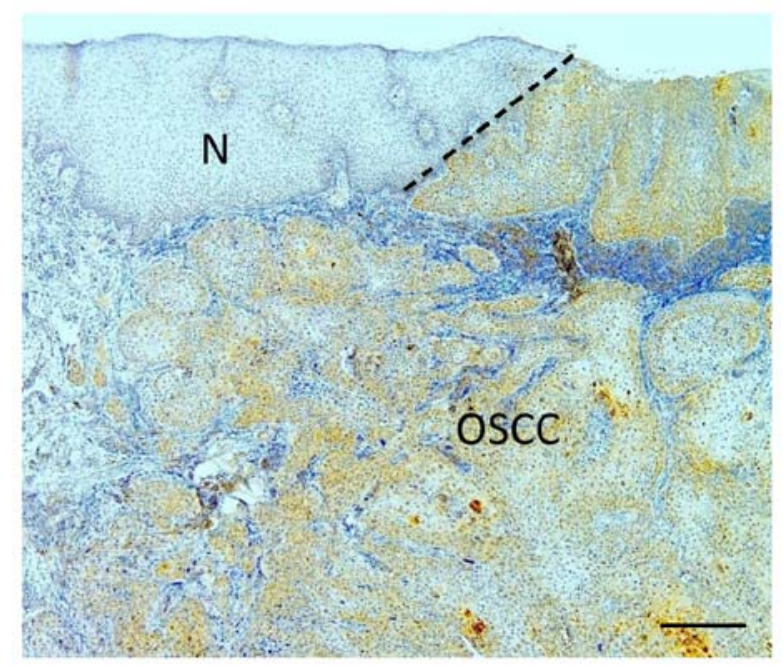

Figure 1. Immunohistochemical staining of RNase 7 in OSCC. The normal epithelium adjacent to the tumor epithelium showed weak immunoreactions in the surface layer ( $\mathrm{N}$ : Normal epithelium). The dashed line indicates the border between the normal epithelium and the OSCC. Tumor cells showed moderate to strong immunoreactions for RNase 7. Scale bars: $200 \mu \mathrm{m}$.

in poorly differentiated OSCC demonstrated weak immunoreactions (Fig. 2E and F).

Expression and concentration of RNase 7 in the cells. The mRNA expression level of RNase 7 was significantly higher in the OSCC cell lines (BSC-OF, SAS, OSC-19, and HSC-2) than in the controls $(\mathrm{P}<0.05$; Fig. 3B). To determine whether the mRNA expression was translated into protein, the presence of intracellular RNase 7 was detected by immunocytochemistry (Fig. 3A). The protein concentration was evaluated in the conditioned medium and the cell extract obtained from each cell line using ELISA. Positive staining for RNase 7 was observed in all the cell lines (Fig. 3A). RNase 7 protein was detected in both the conditioned medium and the cell extracts derived from each cell line. The concentration of RNase 7 was significantly higher in the conditioned media compared to the cell extracts $(\mathrm{P}<0.05$; Fig. S1). The RNase 7 protein levels were significantly higher in the OSCCs compared to the control ( $\mathrm{P}<0.05$; Fig. 4). Knockdown of RNase 7 was performed and confirmed by RT-qPCR after siRNA transfection. The mRNA expression of RNase 7 was significantly lower in the siRNA-OSCC cells compared to the OSCC cells $(\mathrm{P}<0.05$; Fig. 5). Furthermore, cell numbers were significantly higher in the siRNA-BSC-OF, -SAS, -HSC-2, -OSC-19, and -HaCaT cells at $24 \mathrm{~h}$ and siRNA-BSC-OF, -SAS, and -HSC-2 cells at $48 \mathrm{~h}$ when compared with the control OSCC and $\mathrm{HaCaT}$ cells $(\mathrm{P}<0.05$; Fig. 6).

Cell invasion and MMP 9 expression levels. The number of invading cells in the siRNA-BSC-OF, -SAS, and -HSC-2 samples was significantly higher than those in the control OSCC and HaCaT samples ( $\mathrm{P}<0.05$; Fig. 7B). No significant difference in cell numbers between siRNA-OSC-19 and the control was observed. The expression levels of MMP 9 mRNA were significantly higher in the siRNA-BSC-OF, SAS, and HSC-2 cells than in the control OSCC cells $(\mathrm{P}<0.05$; Fig. 7C), which was consistent with the findings of the cell invasion assay. No significant differences in the expression levels of 
A

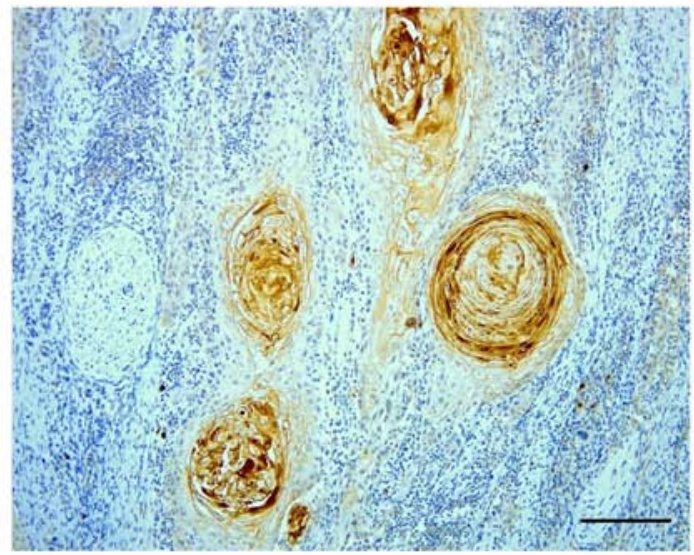

C

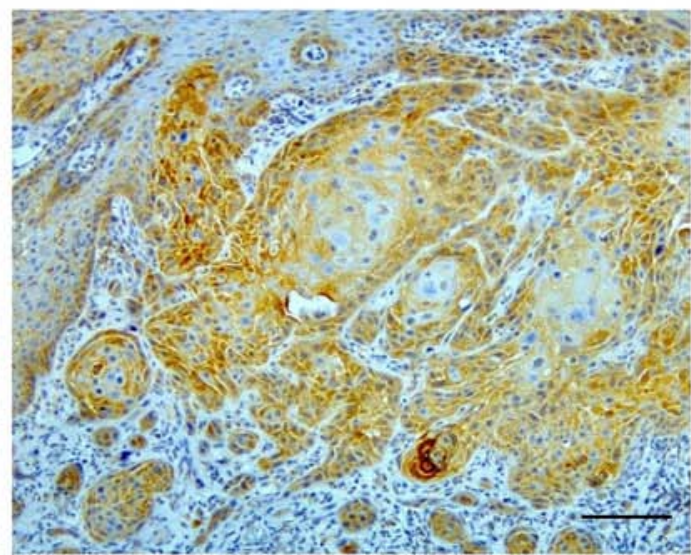

E

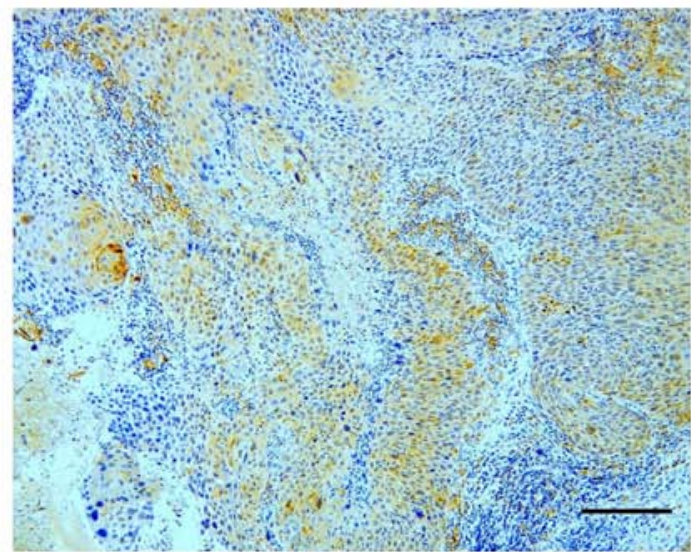

B

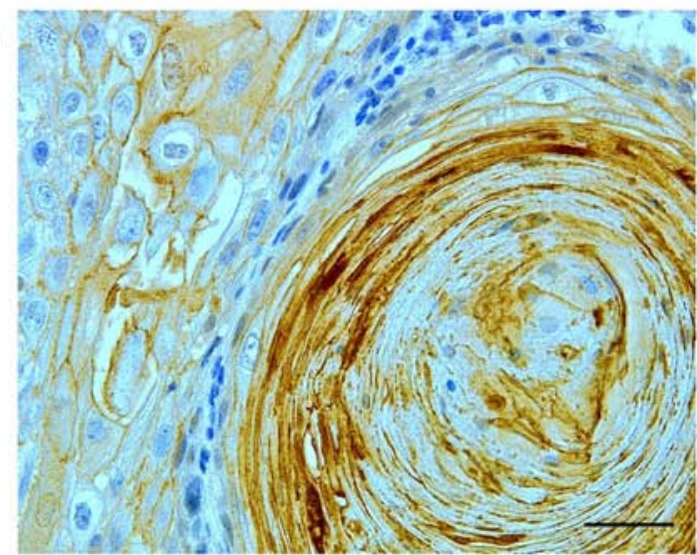

D

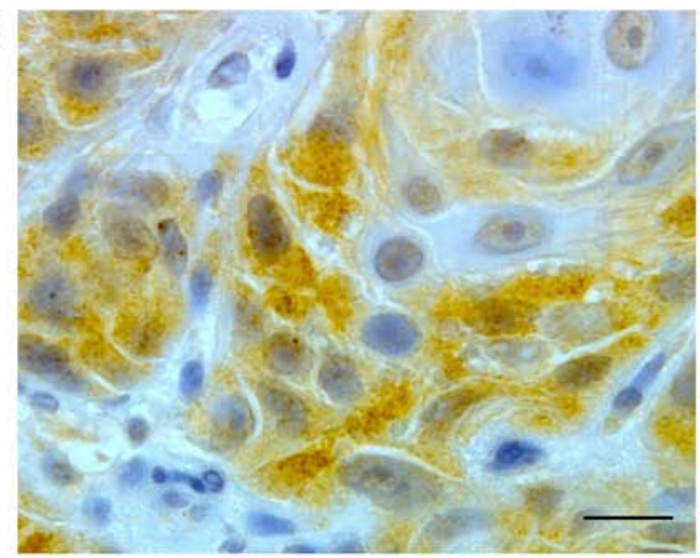

$F$

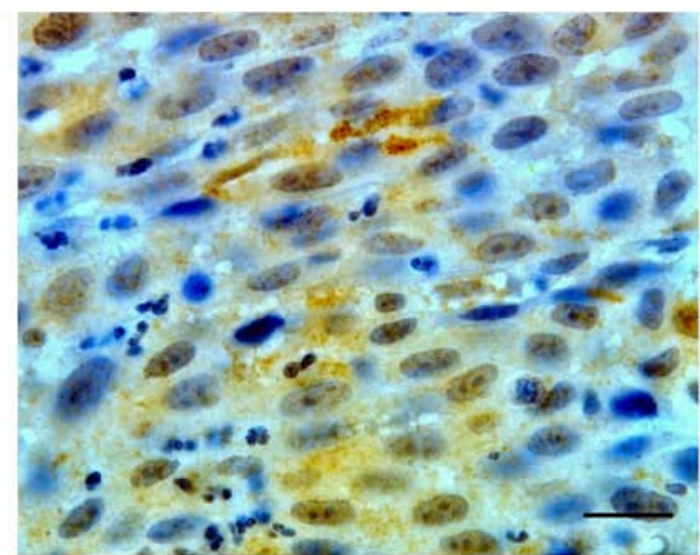

Figure 2. RNase 7 immunostaining in the OSCC cells in relation to cell differentiation. Well-differentiated OSCC showed intense immunoreactions for RNase 7 in the keratin layers of the epithelial pearl and the intercellular spaces of the tumor cells (A and B). Moderately differentiated OSCC showed intense immunoreactions in the nuclei and cytoplasm of the cells in tumor nests containing few areas of keratinization (C and D). Poorly differentiated OSCC showed weak staining in tumor cells with no keratinization (E and F). Scale bars: $100 \mu \mathrm{m}$ (A, C and E); $10 \mu \mathrm{m}$ (B, D and F).

MMP 9 were observed between the siRNA-OSC-19 and siRNA-HaCaT cells.

Expression levels of INV and K14 in the OSCC cells. To examine whether the differentiations were linked to the invasive abilities, the mRNA expression levels of the differentiation and dedifferentiation markers INV and K14, respectively, were evaluated by RT-qPCR. The mRNA expression level of INV was significantly higher in the HSC-2 and SAS cells when compared to the siRNA-HSC-2 and -SAS cells $(\mathrm{P}<0.05$; Fig. 8A). No significant differences in INV expression levels were observed between the siRNA-BSC-OF, -OSC-19, and -HaCaT cells and the control OSCC and HaCaT cells. All the siRNA-OSCC, and -HaCaT cell lines showed significantly higher expression levels of K14 compared to the control OSCC and $\mathrm{HaCaT}$ cells $(\mathrm{P}<0.05$; Fig. $8 \mathrm{~B})$.

\section{Discussion}

The results of the present study have identified the expression levels of RNase 7 in OSCC tissues. Although RNase 7 was localized mainly in the keratinized surface layers of the 

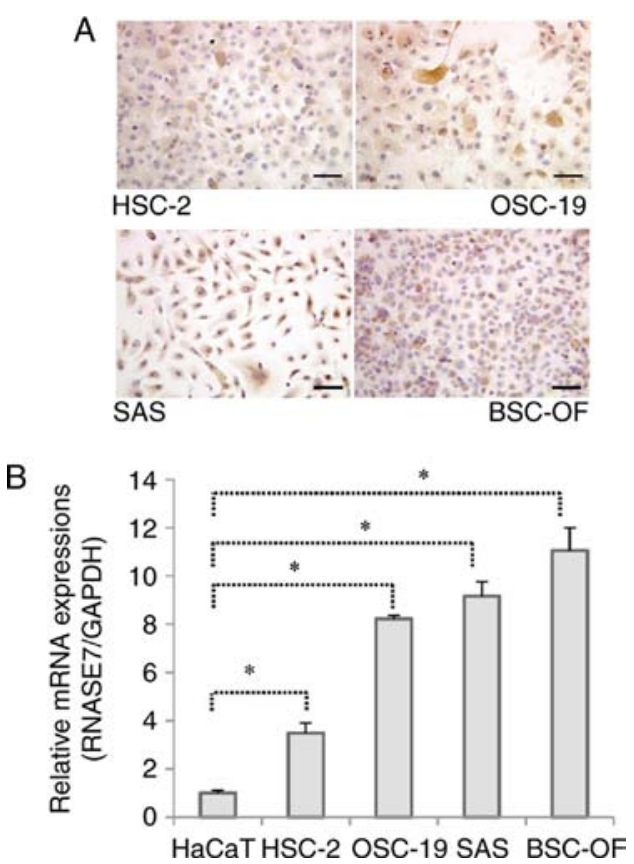

Figure 3. Expression of RNase 7 in the cells. RNase 7 protein was expressed in the cytoplasm and around the nuclei of the OSCC cells (A). The expression levels of RNase 7 were significantly higher in the BSC-OF, SAS, OSC-19, and HSC-2 cells compared to the HaCaT cells (B). Scale bars: $100 \mu \mathrm{m}$ (A). ${ }^{*} \mathrm{P}<0.05$; one way ANOVA, followed by Dunnett's post hoc.

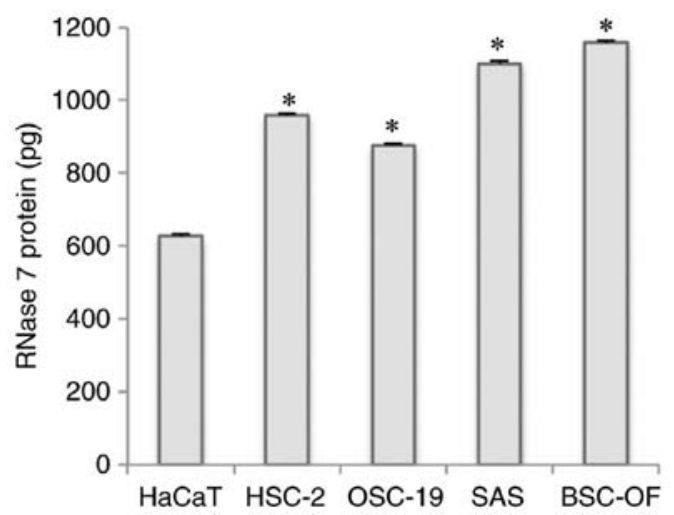

Figure 4. The concentration of RNase 7. Total RNase 7 protein levels were significantly higher $\left({ }^{*} \mathrm{P}<0.05\right)$ in the OSCC cells compared to the HaCaT cells. ${ }^{*} \mathrm{P}<0.05$; one way ANOVA, followed by Dunnett's post hoc.

normal oral epithelium, it was often observed in the basaloid and spinous-like cells and the keratinized pearls of the OSCC tissues. As reported previously in normal and inflamed oral epithelium, the expression of RNase 7 was linked to keratinocyte differentiation in the current study (17). The increased expression of RNase 7 in the keratinized pearl may be due to the differentiation of the cells. The expression of RNase 7 in the basaloid and spinous-like OSCC cells may be in response to an inflammatory stimulus and/or bacterial infection $(1,4)$. OSCC cells have frequently revealed interstitial inflammatory reactions around tumor nests, which are easily infected with bacteria $(18,19)$. The increase in the expression level of the epidermal growth factor receptor (EGFR) in OSCC may be another reason for the RNase 7-positive staining in the basaloid and spinous-like cells. Human carcinomas, including

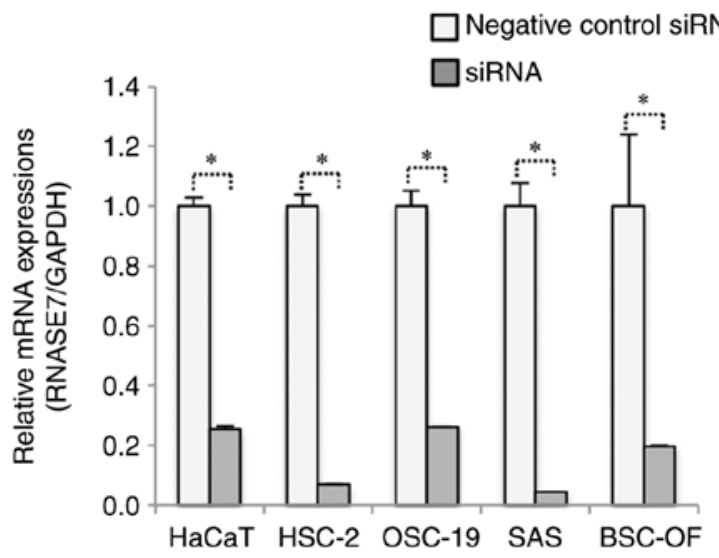

Figure 5. Verification of successful knockdown of RNase 7 in the OSCC cells. The expression levels of RNase 7 were significantly downregulated in the siRNA-OSCC cells when compared to the OSCC cells $\left({ }^{*} \mathrm{P}<0.05\right)$. ${ }^{*} \mathrm{P}<0.05$; Mann Whitney U-test.

OSCC, frequently express high levels of EGFR (20). Moreover, the EGFR signaling pathway is known to induce RNase 7 expression (3); therefore, high expression levels of EGFR may contribute to an increase in the expression of RNase 7 in OSCC cells $(3,21)$. Nonetheless, further investigations are needed to clarify this speculation.

The potential role of $\mathrm{hBD} 2$, an epithelial AMP, in tumor suppression has been previously identified (20). The increased expression of hBD2 in oral carcinoma cells following gene transfection was found to inhibit both proliferation and invasion (22). Therefore, we hypothesized that high expression levels of RNase 7 may play a role in the malignant potential of OSCC cells. By contrast, RNase 7 knockdown promoted the proliferation and invasion of OSCC cells in the current study. Although the invasiveness of the OSC-19 cells was low compared to that of the siRNA-transfected-OSC-19 cells, no significant difference was observed. These results indicate that RNase 7 may function as a tumor suppressor. In addition, other epithelial AMPs such as hBD1 and hBD2 may contribute to tumor suppression $(22,23)$. Thus, RNase 7 may suppress OSCC cell growth and invasion in conjunction with the other epithelial AMPs. Nonetheless, the reason for the high expression levels of RNase 7 in OSCC cells in the current study is unclear. The paracrine and autocrine effects exerted by cancer cells may have induced the expression of this peptide (24).

The expression levels of RNase 7 may vary among cancer cells. The expression profiles of hBDs are known to differ among the various types of cancer cells (25-28); both high and low expression levels of hBD2 have been reported in OSCC $(26,27)$. The role of MMP 9 in the promotion of cell invasion was evaluated because MMP 9 is a key enzyme that promotes cancer cell invasion $(29,30)$. The siRNA-OSCCs showed significantly higher levels of MMP 9 compared to the control OSCCs, except for OSC-19. These data are consistent with those obtained from the invasion assay. The differentiation of the squamous epithelium may be followed by the expression of RNase 7 in the tissue sections. Therefore, we evaluated the level of differentiation of the siRNA-OSCC cells using the differentiation and undifferentiation markers 

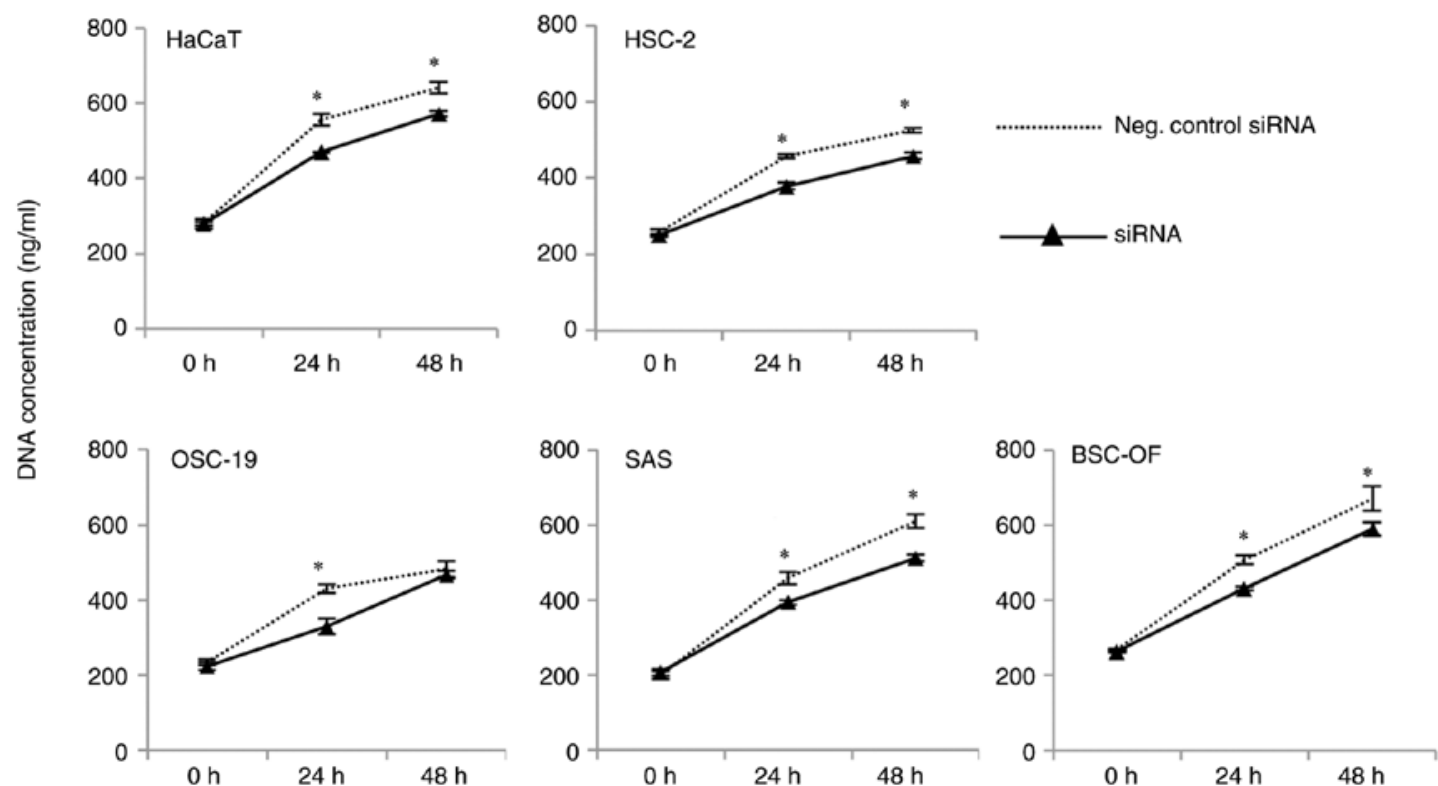

Figure 6. Proliferation of the knockdown OSCC and OSCC cells. The cell numbers were significantly higher ( $\mathrm{P}<0.05)$ in the siRNA-BSC-OF, -SAS, -HSC-2, -OSC-19, and - HaCaT cells compared to the BSC-OF, SAS, HSC-2, OSC-19, and HaCaT cells at $24 \mathrm{~h}$. At $48 \mathrm{~h}$, the cell numbers were significantly higher $\left({ }^{*} \mathrm{P}<0.05\right)$ in the siRNA-BSC-OF, -SAS, -HSC-2, and -HaCaT cells compared to the BSC-OF, SAS, HSC-2, and HaCaT cells. Scale bars: $100 \mu \mathrm{m}(\mathrm{A}) .{ }^{*} \mathrm{P}<0.05$; Student's t-test.

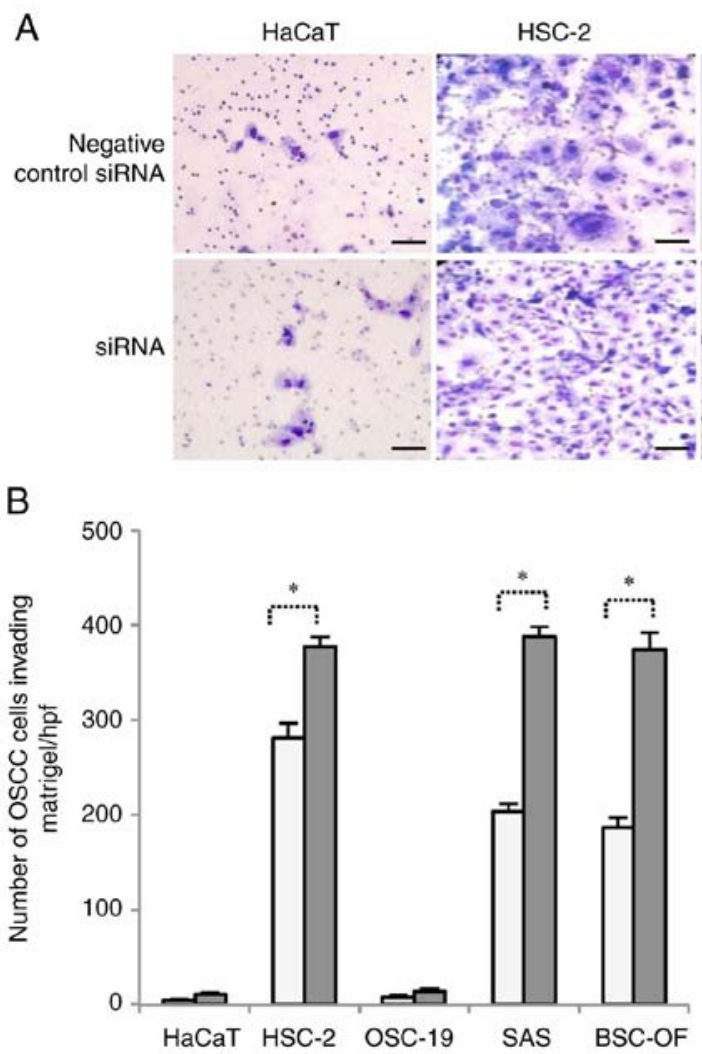

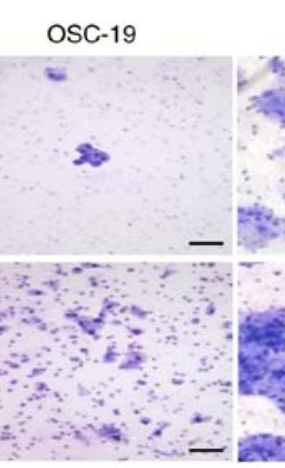

C

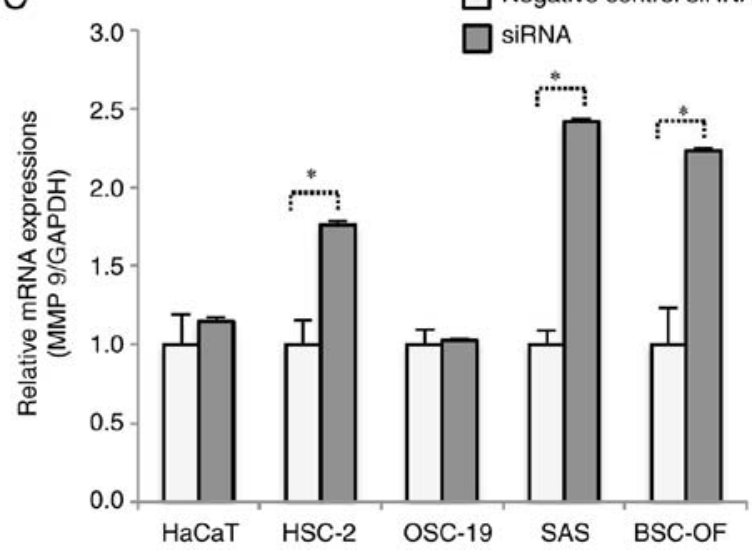

Figure 7. Cell invasion and MMP 9 expression levels. Negative control-HaCaT, HSC-2, OSC-19, SAS, BSC-OF, and siRNA-HaCaT, -HSC-2, -OSC-19, -SAS and -BSC-OF cells invading through the Matrigel (A). Scale bars: $100 \mu \mathrm{m}$. The number of invading cells among the siRNA-BSC-OF, -SAS, and -HSC-2 cells was significantly higher ("P<0.05) than that among the BSC-OF, SAS, and HSC-2 cells. ${ }^{*} \mathrm{P}<0.05$; Student's t-test (B). The expression level of MMP 9 was significantly higher ( $\mathrm{P}<0.05)$ in the siRNA-BSC-OF, -SAS, and -HSC-2 cells compared to the BSC-OF, SAS, and HSC-2 cells (C). ${ }^{*} \mathrm{P}<0.05$; Mann Whitney U-test.

INV and K14, respectively. The downregulated expression of RNase 7 in cancer cells may induce dedifferentiation in OSCC. In general, undifferentiated cancer cells grow more rapidly than differentiated cancer cells (31). These results indicate that RNase 7 may function as a suppressor of tumor growth and invasion. The associations between MMP 9 
A

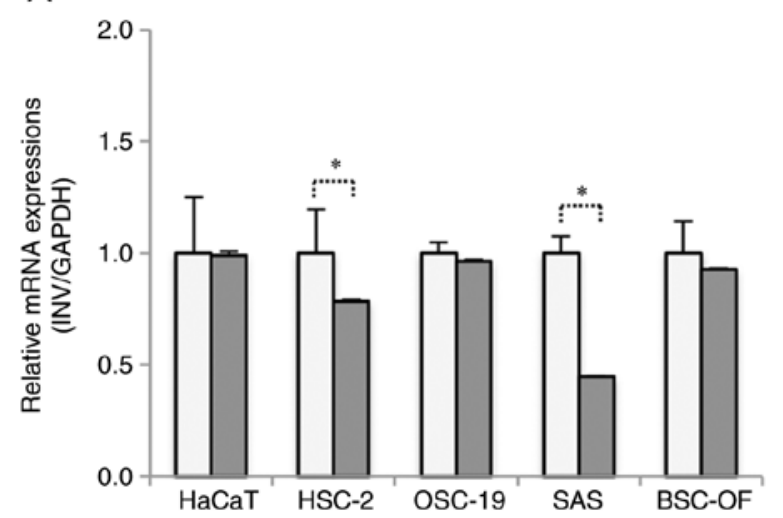

B

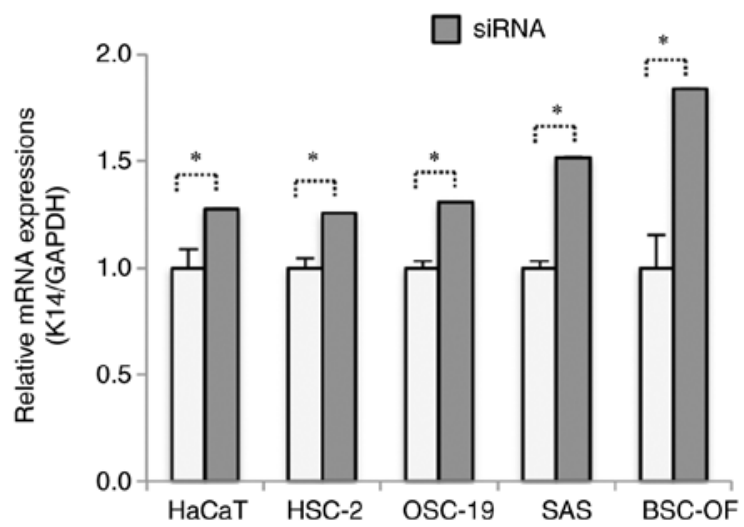

Figure 8. Expression levels of INV and K14 in the OSCC cells. The expression level of INV was significantly lower ( $\mathrm{P}<0.05)$ in the siRNA- HSC-2, and -SAS cells compared to the HSC-2 and SAS cells (A). K14 levels in siRNA-OSCC and -HaCaT cells were significantly higher ( $\mathrm{P}<0.05)$ than those in the OSCC and $\mathrm{HaCaT}$ cells (B). * $\mathrm{P}<0.05$; Mann Whitney U-test.

expression and dedifferentiation and the induction of both proliferation and invasion by the downregulated expression of RNase 7 in OSCC cells remain unknown. K14 may play a role in maintaining the cell proliferation potential in the basal layer of the stratified epithelia by modulating phosphatidylinositol 3-kinase/Akt-mediated cell proliferation (PI3K/Akt) (32). The expression levels of both RNase 7 and MMP 9 can be regulated by the PI3K/Akt signaling pathway $(33,34)$. A previous study showed that siRNA-mediated downregulation of Notch2 in gastric cancer cells could increase tumor cell invasion and enhance MMP 9 expression via the PI3K/Akt signaling pathway (35). Therefore, the increase in cell proliferation, MMP 9 expression, and invasion during the downregulation of RNase 7 may have been regulated by the PI3K/Akt signaling pathway in the present study. Further studies were needed to clarify this hypothesis. The stimulation of keratinocyte differentiation in vitro has been shown to induce MMP 9 secretion (36). On the contrary, increased MMP 9 expression followed by keratinocyte dedifferentiation was observed in the siRNA-OSCC cells in the present study. The high expression levels of MMP 9 in this study may have been induced by pathways that are different from those involved in keratinocyte differentiation. MMP 9 expression is strongly associated with the EGFR signaling pathway (37). High EGFR expression levels may contribute to high levels of RNase 7 expression in OSCC. EGFR stimulation may induce the expression of MMP 9 in cells with decreased RNase 7 expression levels. Further investigations are needed to elucidate the mechanisms involved in the promotion of the proliferation and invasion of siRNA-OSCC cells.

In conclusion, RNase 7, an epithelial antimicrobial peptide, is widely expressed in OSCC. The upregulated expression of RNase 7 in OSCC suggests its involvement in tumor development and growth. However, decreased RNase 7 expression was found to promote the growth and invasion of the OSCC cells in this study. Thus, RNase 7 may contribute to the suppression of the malignant potential of these cells.

\section{Acknowledgements}

Not applicable.

\section{Funding}

This research did not receive any specific grant from funding agencies in the public, commercial, or not-for-profit sectors.

\section{Availability of data and materials}

The datasets used and/or analyzed during the current study are available from the corresponding author on reasonable request.

\section{Authors' contributions}

YA, KY and MS conceived and designed the study. PN conducted the experiments. YK, TM, and OU analyzed the data and interpreted the results data and DP, KY and JS performed the statistical analysis. PN and YA wrote the manuscript. MS, OU, and KY reviewed and edited the manuscript. All authors read and approved the manuscript and agree to be accountable for all aspects of the research in ensuring that the accuracy or integrity of any part of the work is appropriately investigated and resolved.

\section{Ethics approval and consent to participate}

Approval for the study was obtained from the ethics review board of the Institute of Personalized Medical Science, Health Sciences University of Hokkaido (approval no. 2012-005). All the patients provided written informed consent for this study.

\section{Patient consent for publication}

Not applicable.

\section{Competing interests}

The authors declare that they have no competing interests.

\section{References}

1. Harder J and Schroder JM: RNase 7, a novel innate immune defense antimicrobial protein of healthy human skin. J Biol Chem 277: 46779-46784, 2002. 
2. Spencer JD, Schwaderer AL, Dirosario JD, McHugh KM McGillivary G, Justice SS, Carpenter AR, Baker PB, Harder J and Hains DS: Ribonuclease 7 is a potent antimicrobial peptide within the human urinary tract. Kidney Int 80: 174-180, 2011.

3. Amatngalim GD, Broekman W, Daniel NM, van der Vlugt LE and Hiemstra PS: Cigarette smoke impairs basal cell mediated epithelial wound repair and induces expression of the antimicrobial protein RNase 7 via oxidative stress. Eur Respir J 46 (Suppl 59): PA5047, 2015

4. Eberhard J, Menzel N, Dommisch H, Winter J, Jepsen S and Mutters R: The stage of native biofilm formation determines the gene expression of human beta-defensin-2, psoriasin, ribonuclease 7 and inflammatory mediators: A novel approach for stimulation of keratinocytes with in situ formed biofilms. Oral Microbiol Immunol 23: 21-28, 2008.

5. Köten B, Simanski M, Gläser R, Podschun R, Schröder JM and Harder J: RNase 7 contributes to the cutaneous defense against enterococcus faecium. PLoS One 4: e6424, 2009.

6. Simanski M, Dressel S, Gläser R and Harder J: RNase 7 protects healthy skin from staphylococcus aureus colonization. J Invest Dermatol 130: 2836-2848, 2010.

7. Weinberg A, Jin G, Sieg S and McCormick TS: The yin and yang of human beta-defensins in health and disease. Front Immunol 3 : 294, 2012.

8. Ghosh SK, McCormick TS and Weinberg A: Human beta defensins and cancer: Contradictions and common ground. Front Oncol 9: 341, 2019.

9. Liu Y, Bunston C, Hodson N, Resaul J, Sun PH, Cai S, Chen G, $\mathrm{Gu}$ Y, Satherley LK, Bosanquet DC, et al: Psoriasin promotes invasion, aggregation and survival of pancreatic cancer cells; association with disease progression. Int J Oncol 50: 1491-1500, 2017.

10. Algermissen B, Sitzmann J, LeMotte P and Czarnetzki B Differential expression of CRABP II, psoriasin and cytokeratin 1 mRNA in human skin diseases. Arch Dermatol Res 288: 426-430, 1996

11. Chen X, Zou X, Qi G, Tang Y, Guo Y, Si J and Liang L: Roles and mechanisms of human cathelicidin LL-37 in cancer. Cell Physiol Biochem 47: 1060-1073, 2018.

12. Kahlenberg JM and Kaplan MJ: Little peptide, big effects: The role of LL-37 in inflammation and autoimmune disease. J Immunol 191: 4895-4901, 2013.

13. Ross KF and Herzberg MC: Calprotectin expression by gingival epithelial cells. Infect Immun 69: 3248-3254, 2001.

14. Scola N, Gambichler T, Saklaoui H, Bechara FG, Georgas D, Stücker M, Gläser R and Kreuter A: The expression of antimicrobial peptides is significantly altered in cutaneous squamous cell carcinoma and precursor lesions. Br J Dermatol 167: 591-597, 2012

15. Abiko Y, Okumura K, Ohuchi T, Konishi T, Kanazawa M and Kaku T: Basaloid-squamous cell carcinoma of the floor of the mouth: Characterization of a cell line. J Oral Pathol Med 26 : 367-370, 1997

16. Livak KJ and Schmittgen TD: Analysis of relative gene expression data using real-time quantitative PCR and the 2(-Delta Delta C(T)) method. Methods 25: 402-408, 2001.

17. Neopane P, Paudel D, Yoshida K, Raj Adhikari B, Morikawa T, Onishi A, Hiraki D, Uehara O, Sato J, Nishimura MA, et al: Immunohistochemical localization of RNase 7 in normal and inflamed oral epithelia and salivary glands. Acta Histochem Cytochem 52: 35-43, 2019.

18. Abiko Y, Suraweera AK, Nishimura M, Arakawa T, Takuma T, Mizoguchi I and Kaku T: Differential expression of human beta-defensin 2 in keratinized and non-keratinized oral epithelial lesions; immunohistochemistry and in situ hybridization. Virchows Arch 438: 248-253, 2001.

19. Pushalkar S, Ji X, Li Y, Estilo C, Yegnanarayana R, Singh B Li X and Saxena D: Comparison of oral microbiota in tumor and non-tumor tissues of patients with oral squamous cell carcinoma BMC Microbiol 12: 144, 2012.

20. Grandis JR and Tweardy DJ: TGF-alpha and EGFR in head and neck cancer. J Cell Biochem Suppl 17F: 188-191, 1993.
21. Sheikh Ali MA, Gunduz M, Nagatsuka H, Gunduz E, Cengiz B, Fukushima K, Beder LB, Demircan K, Fujii M, Yamanaka $\mathrm{N}$, et al: Expression and mutation analysis of epidermal growth factor receptor in head and neck squamous cell carcinoma. Cancer Sci 99: 1589-1594, 2008.

22. Kamino Y, Kurashige Y, Uehara O, Sato J, Nishimura M, Yoshida K, Arakawa T, Nagayasu H, Saitoh M and Abiko Y: HBD-2 is downregulated in oral carcinoma cells by DNA hypermethylation, and increased expression of hBD-2 by DNA demethylation and gene transfection inhibits cell proliferation and invasion. Oncol Rep 32: 462-468, 2014.

23. Sun CQ, Arnold R, Fernandez-Golarz C,Parrish AB, Almekinder T, He J, Ho SM, Svoboda P, Pohl J, Marshall FF and Petros JA: Human beta-defensin-1, a potential chromosome $8 \mathrm{p}$ tumor suppressor: Control of transcription and induction of apoptosis in renal cell carcinoma. Cancer Res 66: 8542-8549, 2006.

24. Tsujikawa T, Yaguchi T, Ohmura G, Ohta S, Kobayashi A, Kawamura N, Fujita T, Nakano H, Shimada T, Takahashi T, et al: Autocrine and paracrine loops between cancer cells and macrophages promote lymph node metastasis via CCR4/CCL22 in head and neck squamous cell carcinoma. Int J Cancer 132: 2755-2766, 2013.

25. Kesting MR, Loeffelbein DJ, Hasler RJ, Wolff KD, Rittig A, Schulte M, Hirsch T, Wagenpfeil S, Jacobsen F and Steinstraesser L: Expression profile of human beta-defensin 3 in oral squamous cell carcinoma. Cancer Invest 27: 575-581, 2009.

26. Yoshimoto T, Yamaai T, Mizukawa N, Sawaki K, Nakano M, Yamachika E and Sugahara T: Different expression patterns of beta-defensins in human squamous cell carcinomas. Anticancer Res 23: 4629-4633, 2003.

27. Abiko Y, Mitamura J, Nishimura M, Muramatsu T, Inoue T, Shimono M and Kaku T: Pattern of expression of beta-defensins in oral squamous cell carcinoma. Cancer Lett 143: 37-43, 1999.

28. Sawaki K, Mizukawa N, Yamaai T, Yoshimoto T, Nakano M and Sugahara T: High concentration of beta-defensin-2 in oral squamous cell carcinoma. Anticancer Res 22: 2103-2107, 2002.

29. Björklund M and Koivunen E: Gelatinase-mediated migration and invasion of cancer cells. Biochim. Biochim Biophys Acta 1755: 37-69, 2005

30. Egeblad M and Werb Z: New functions for the matrix metalloproteinases in cancer progression. Nat Rev Cancer 2: 161-174, 2002.

31. Bullock S and Hales M: Neoplasia: In: Babey AM (ed). Principles of pathophysiology, chapter 4. Pearson Higher Education AU, pp66, 2012.

32. Alam H, Sehgal L, Kundu ST, Dalal SN and Vaidya MM: Novel function of keratins 5 and 14 in proliferation and differentiation of stratified epithelial cells. Mol Biol Cell 22: 4068-4078, 2011.

33. Eichler TE, Becknell B, Easterling RS, Ingraham SE, Cohen DM, Schwaderer AL, Hains DS, Li B, Cohen A, Metheny J, et al: Insulin and the phosphatidylinositol 3-kinase signaling pathway regulate ribonuclease 7 expression in the human urinary tract. Kidney Int 90: 568-579, 2016.

34. Wang Y, Wan D, Zhou R, Zhong W, Lu S and Chai Y: Geraniin inhibits migration and invasion of human osteosarcoma cancer cells through regulation of PI3K/Akt and ERK1/2 signaling pathways. Anticancer Drugs 28: 959-966, 2017.

35. Guo LY, Li YM, Qiao L, Liu T, Du YY, Zhang JQ, He WT, Zhao YX and He DQ: Notch2 regulates matrix metallopeptidase 9 via PI3K/AKT signaling in human gastric carcinoma cell MKN-45. World J Gastroenterol 18: 7262-7270, 2012.

36. Kobayashi T, Hattori S, Nagai Y and Tajima S: Differential regulation of the secretions of matrix metalloproteinase- 9 and tissue inhibitor of metalloproteinases-1 from human keratinocytes in culture. IUBMB Life 50: 221-226, 2000

37. O-charoenrat P, Modjtahedi H, Rhys-Evans P, Court WJ, Box GM and Eccles SA: Epidermal growth factor-like ligands differentially up-regulate matrix metalloproteinase 9 in head and neck squamous carcinoma cells. Cancer Res 60: 1121-1128, 2000. 